\title{
Numerical Study of Electromagnetic Loss and Heat Transfer in an Oil-Immersed Transformer
}

\author{
Wen-Rong Si $\mathbb{D}^{1},{ }^{1}$ Chen-Zhao Fu, ${ }^{1}$ Xu-Tao $W u,{ }^{2}$ Xiu Zhou, ${ }^{2}$ Xiu-Guang Li, $^{2}$ Yi-Ting Yu, ${ }^{3}$ \\ Xiao-Yu Jia, ${ }^{4}$ and Jian Yang $\mathbb{D}^{4}$ \\ ${ }^{1}$ State Grid Shanghai Electrical Power Research Institute, Shanghai 200437, China \\ ${ }^{2}$ State Grid Ningxia Electrical Power Research Institute, Yinchuan 750001, China \\ ${ }^{3}$ MOE Key Laboratory of Micro/Nano Systems for Aerospace, Northwestern Polytechnical University, Xi'an 710072, China \\ ${ }^{4}$ MOE Key Laboratory of Thermo-Fluid Science and Engineering, Xi'an Jiaotong University, Xi'an 710049, China
}

Correspondence should be addressed to Jian Yang; yangjian81@mail.xjtu.edu.cn

Received 26 June 2020; Revised 8 September 2020; Accepted 11 September 2020; Published 28 September 2020

Academic Editor: Hervé Laurent

Copyright (c) 2020 Wen-Rong Si et al. This is an open access article distributed under the Creative Commons Attribution License, which permits unrestricted use, distribution, and reproduction in any medium, provided the original work is properly cited.

Transformer is one of the most important pieces of equipment in power system. The insulation aging and lifespan of transformer are significantly affected by hot spot distributions of internal components inside. In the present paper, the electromagnetic losses of different components and heat transfer process in a three-phase forced oil circulation transformer $(400 \mathrm{kVA}-15 \mathrm{kV} / 400 \mathrm{~V})$ are numerically studied with finite element method. The leakage magnetic flux and eddy current loss density for metal components and oil tank are carefully analyzed, and the effect of metal components' electromagnetic loss on hot spot temperature of different components and oil flow in transformer is also studied. It is found that the surface current of metal components is generated by leakage magnetic flux, and surface current density is large when leakage magnetic flux concentrates. The effect caused by relative magnetic permeability of metal components is remarkable on electromagnetic loss of metal components and oil tank, while the effect caused by relative magnetic permeability of transformer tank is relatively small. Due to the mixing of metal components on oil flow, the heat transfer of core is enhanced, its hot spot temperature is lowered, and the hot spot locations of coil and core also change. These results are meaningful for further understanding of heat transfer process in transformer and important for the optimal design of transformer.

\section{Introduction}

Transformer is one of the most important pieces of electrical equipment in power system. Once transformer is out of work, it will seriously affect the safety operation of power system and cause huge economic loss [1].

For transformer operation process, it is often affected by electromagnetic, mechanical, chemical, and thermal stress factors, which will lead to stability and safety problems for long-time operations [2]. Generally, the hot spot temperature in transformer is often used to monitor operating status for transformer [3]. Due to the difficulty in real-time detection of hot spot temperature in transfer, the calculation methods are often used to predict the hot spot locations in transformer, including the lumped parameter method and numerical method. For the lumped parameter method, such as thermoelectricity analogy $[4,5]$ and temperature rise guidelines $[6,7]$, the detailed information for oil flow and temperature distributions for different components in transformer cannot be obtained, and the prediction accuracy would be questionable. For numerical method, although it is time-consuming, the detailed information of local oil flow and temperature distributions in transformer can be captured, and the results should be more reliable. For example, the additional winding eddy current loss due to nonlinear loads was considered in the numerical simulations by Ebenezer et al. [8] to determine hot spot temperature rise in a dry-type three-phase transformer. The numerical methodology was validated by experiments. The correlations for hot spot temperature as a function of total harmonic distortion were 
proposed, which was used to estimate transformer's life under different loads. The local oil flow and temperature distributions in low-voltage coil for a disc transformer were numerically studied by Torriano et al. [9] with threedimensional conjugate heat transfer model. It is found that, due to the effects of sticks and duct spacers in oil flow channel of coil, the circumferential velocity and temperature gradients of coil are relatively larger. Tsili et al. [10] numerically predicted the heat transfer performance in a transformer, where the thermal property variations of winding and cooling oil with temperature were fully considered and coupled for the simulations. Since the structure of transformer is quite complex, most of numerical studies for electromagnetic, oil flow and heat transfer simulations were performed based on a simplified model, where the electromagnetic loss of each component was determined first, and then the oil flow and temperature distributions were simulated. For example, Liao et al. [11] firstly calculated the magnetic flux density in a transformer. Then the electromagnetic loss of winding was calculated and used to simulate oil flow and temperature distributions in the transformer. Similar studies were also performed by Liu et al. [12], and the oil flow and temperature distributions in the transformer under different load rates were obtained with finite volume method (FVM). Agheb and Hoidalen [13] introduced an accurate model to investigate the spatial distribution of magnetic flux density inside the core. It has been expressed that the nonuniform flux distribution can lead to higher maximum core temperature. Besides, the magnetic field and temperature distributions in transformer were also studied by Lan et al. [14] with FEM and FVM methods, and the numerical results can fit well with the experimental results. As transformer capacity increases, the magnetic leakage of transformer will become more and more serious. The leakage magnetic flux will produce inhomogeneous eddy current losses on surfaces of metal components and oil tank and lead to local overheating in the transformer [15]. Milagre et al. [16] numerically studied the leakage magnetic field in a transformer, where the surface impedance concept was adopted for the simulations, and the eddy current losses on the surface of metal components, oil tank, and magnetic shielding plates were obtained. The eddy current losses on surfaces of metal components and total electromagnetic loss of transformer installed with vertical or horizontal magnetic shunt plates were numerically studied by Moghaddami et al. [17]. It was found that the eddy current losses of metal components can be reduced by magnetic shunt plates, and the effect of vertical magnetic shunt plate is better. The eddy current losses on surfaces of metal components and oil tank of a three-phase distribution transformer with unbalanced voltage excitation were numerically studied by Njafi et al. [18]. It was found that if the coil voltage is high, the leakage magnetic flux on the surface of oil tank near the coil is higher.

Based on above literature survey, it is shown that the heat transfer process in transformer is quite complex, and the corresponding computational models may be oversimplified [19] for electromagnetic, oil flow and heat transfer coupled simulations. Most simulations may ignore the metal components inside the transformer, and the geometrical models for the transformers may be twodimensional. Furthermore, the effects of stray loss caused by inhomogeneous leakage magnetic field on the overall temperature rise and oil velocity distributions in the transformer may not be considered. The local overheating of metal components in transformer caused by inhomogeneous leakage magnetic distributions and the effects of eddy current losses of metal components and oil tank on oil flow and heat transfer for different components in the transformer are still quite unclear. Therefore, in the present paper, the electromagnetic losses of different components and heat transfer process in a three-dimensional three-phase forced oil circulation transformer are numerically studied with finite element method. The leakage magnetic flux and eddy current loss density for metal components and oil tank are analyzed, and the effect of metal components' electromagnetic loss on hot spot temperature of different components and oil flow in transformer is studied. The present study should be meaningful for further understanding of the principle of electromagnetic-heat-flow interactions and improving accuracy of hot spot prediction in the transformer, which would also be important and helpful for the optimal design of transformer.

\section{Methodology}

2.1. Physical Model and Geometric Parameters. In the present study, a three-phase forced oil circulation transformer $(400 \mathrm{kVA}-15 \mathrm{kV} / 400 \mathrm{~V})$ is selected for the simulation, where the physical model and geometric diameters are presented in Figure 1. It includes transformer oil tank (Figure 1(a)), transformer components (Figure 1(b)), and winding (Figure 1(c)).

The dimensions for transformer oil tank are $2 \mathrm{~m}(x) \times$ $1.2 \mathrm{~m}(y) \times 1.80 \mathrm{~m}(z)$. Three oil inlets and three oil outlets are horizontally arranged near the top and bottom of the tank, and the distances from oil inlet to the top or from oil outlet to the bottom are $35 \mathrm{~cm}$. Furthermore, the distances between adjacent oil inlets or between outlets are $55 \mathrm{~cm}$, the diameters of the oil inlet or outlet are $16 \mathrm{~cm}$, and the oil inlet velocity is $0.2 \mathrm{~m} / \mathrm{s}$. Since the thickness of tank wall is quite thin $(2 \mathrm{~mm}-8 \mathrm{~mm})$, its thermal conduction is neglected for the simulations. The metal components inside transformer include yoke clamp and pulling plates. The thickness of the yoke clamp is $1 \mathrm{~cm}$, which is used to clamp the silicon steel sheets of core. A metal plate with thickness of $3 \mathrm{~cm}$ is located on the upper yoke clamp, which is used to fix pulling plates, and pulling plates are used to support the yoke clamp. The winding is fixed by metal components and the core is wound by coil, where the external coil is with high voltage and internal coil is with low voltage. A small gap filled with cooling oil exists between the external and internal voltage coils. Both the coil and core phases along the $x$-coordinate are phase $A$, phase $B$, and phase $C$, where the phase difference for sinusoidal electrical excitation of adjacent coils is $2 \pi / 3$. Typical physical properties for different components in the transformer are listed in Table 1, which is provided as in COMSOL Multiphysics 5.2 [20]. 


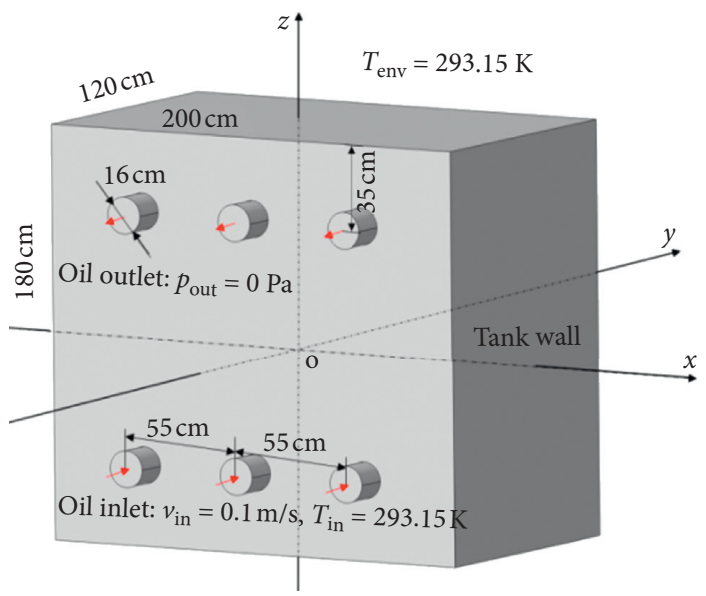

(a)

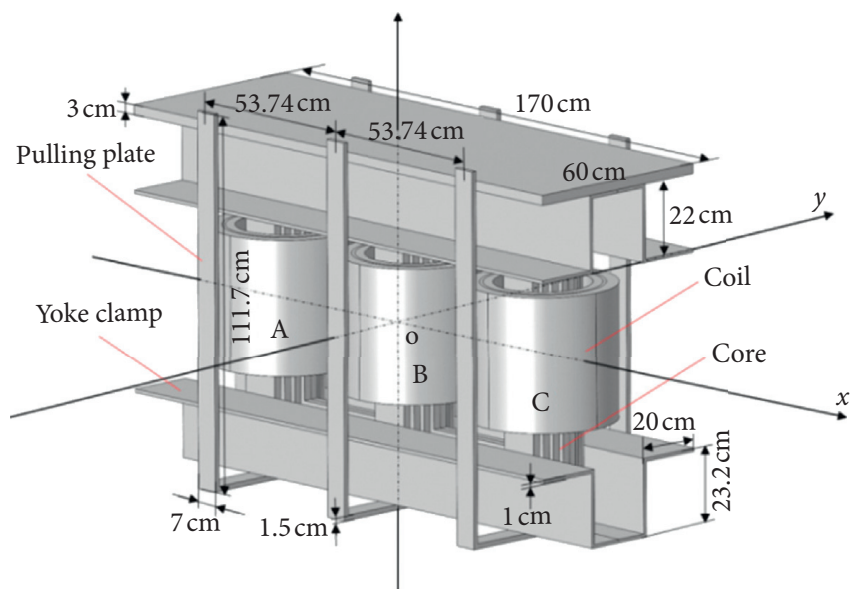

(b)

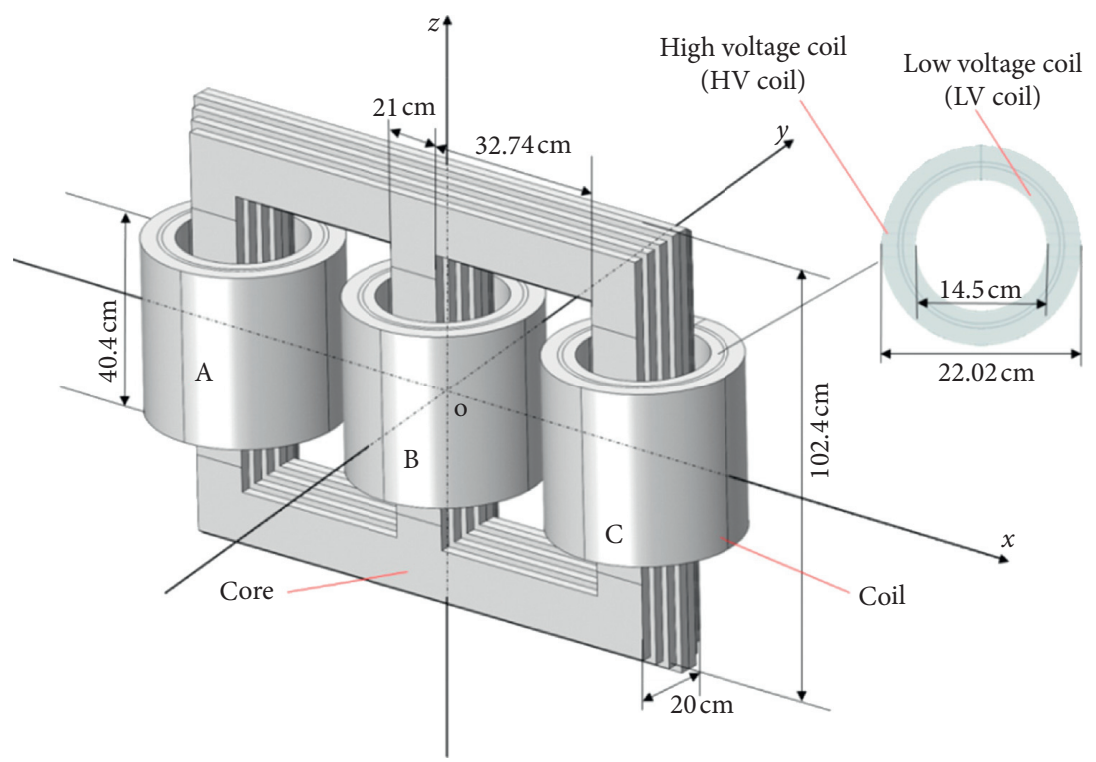

(c)

Figure 1: Physical model for transformer. (a) Oil tank. (b) Metal components (yoke clamp and pulling plates) and winding. (c) Winding (coil and core).

The variations of heat capacity $\left(c_{\mathrm{p}}\right)$ and thermal conductivity $(\lambda)$ for different components with temperature are formulated as follows [10]:

$$
\begin{aligned}
c_{p, \text { iron }}(T) & =-2.91 \times 10^{-4} \times(T-273.15)^{2}+0.522 \times(T-273.15)+431.88, \\
c_{p, \text { copper }}(T) & =-3.20 \times 10^{-4} \times(T-273.15)^{2}+0.221 \times(T-273.15)+376.98, \\
\lambda_{\text {iron }}(T) & =8.64 \times 10^{-5} \times(T-273.15)^{2}-0.104 \times(T-273.15)+404.18, \\
\lambda_{\text {copper }}(T) & =1.22 \times 10^{-4} \times(T-273.15)^{2}-0.128 \times(T-273.15)+83.71 .
\end{aligned}
$$

Magnetic loss introduces a complex relative permeability and it is intended for time-harmonic (frequency domain) studies, which select $\mu^{\prime}$ and $\mu^{\prime \prime}$ (dimensionless) to describe the relative permeability as a complex-valued quantity [21], 
TABLE 1: Typical physical properties for different components in the transformer [20].

\begin{tabular}{lccccc}
\hline Component & Material & $\begin{array}{c}\text { Thermal conductivity } \\
(\mathrm{W} /(\mathrm{m} \cdot \mathrm{K}))\end{array}$ & Heat capacity $(\mathrm{J} /(\mathrm{kg} \cdot \mathrm{K})$ & Electronic conductivity $(\mathrm{S} / \mathrm{m})$ & Relative permeability \\
\hline Coil & Copper & $\lambda_{\text {copper }}(T)$ & $c_{\mathrm{p}, \text { copper }}(T)$ & $6 \times 10^{7}$ & 1 \\
Core & Soft iron & $\lambda_{\text {iron }}(T)$ & $c_{\mathrm{p}, \text { iron }}(T)$ & 0.1 & $\mu_{\mathrm{r}}$ \\
Metal component & Iron & $\lambda_{\text {iron }}(T)$ & $c_{\mathrm{p}, \text { iron }}(T)$ & $1.12 \times 10^{7}$ & 50 \\
Oil tank & Steel & 76.2 & 440 & $1.12 \times 10^{7}$ & 600 \\
\hline
\end{tabular}

and it is formulated as follows:

$$
\mu_{\mathrm{r}}=\mu^{\prime}-j \mu^{\prime \prime}=950-j 30,
$$

where $\mu^{\prime}$ is the real part and it represents the magnetic storage capacity, $\mu^{\prime \prime}$ is the imaginary part and it represents the magnetic loss capacity, and $j$ is the imaginary unit of plural.

2.2. Governing Equations and Computational Methods. Firstly, the electromagnetic analysis is performed for the transformer. When the coil is under sinusoidal electrical excitation, the governing equations for electromagnetic field are as follows:

$$
\left\{\begin{array}{l}
-\omega^{2} \gamma \vec{A}+j \omega \sigma \vec{A}+\nabla \times\left(\mu^{-1} \nabla \times \vec{A}\right)=0, \\
\nabla \times \vec{A}=\vec{B} ; \quad \vec{E}=-j \omega \vec{A} ; \vec{B}=\mu \vec{H} ; \vec{J}=\sigma \vec{E},
\end{array}\right.
$$

where $\vec{A}$ is the magnetic vector potential, $\mathrm{Wb} / \mathrm{m} ; \vec{B}$ is the intensity of magnetization, $T ; \vec{E}$ is the electric field intensity, $\mathrm{N} / \mathrm{C} ; \vec{H}$ is the magnetic field intensity, $\mathrm{A} / \mathrm{m} ; \vec{J}$ is the current density, $\mathrm{A} / \mathrm{m}^{2} ; j$ is the imaginary unit; $\omega$ is the phase angle at $2 \pi f$, rad; $f$ is the electrical excitation frequency at $50 \mathrm{~Hz} ; \gamma$ is the dielectric constant, $\mathrm{F} / \mathrm{M} ; \mu$ is the magnetic permeability, $\mathrm{H} / \mathrm{m} ; \sigma$ is the electrical conductivity, $\mathrm{S} / \mathrm{m}$.

The skin depth $(\delta)$ of metal components and oil tank wall is formulated in equation (4). Since skin depth is much smaller than geometric dimensions of components, the electric and magnetic fields are mainly concentrated on the conductor surfaces. In order to simplify simulations, the surface impedance boundary condition is used to describe the relationship between electric and magnetic fields on conductor surfaces, and the computations would be reduced [22]. In the present study, the correlation between electric and magnetic fields on the surfaces of metal components and oil tank is given by COMSOL Multiphysics 5.2 [20], which is presented in equation (5).

$$
\begin{gathered}
\delta=\sqrt{\frac{2}{\omega \sigma \mu_{0} \mu_{\mathrm{r}}}}=\sqrt{\frac{2}{\omega \sigma \mu}}, \\
\sqrt{\frac{\mu_{0} \mu_{\mathrm{r}}}{\gamma_{0} \gamma_{\mathrm{r}}-j(\sigma / \omega)}} \vec{n} \times \vec{H}+\vec{E}-(\vec{n}-\vec{E}) \vec{n} \\
=\left(\vec{n} \cdot \vec{E}_{\mathrm{s}}\right) \vec{n}-\vec{E}_{\mathrm{s}},
\end{gathered}
$$

where $\vec{E}_{s}$ is the tangential component of electric field strength; $\vec{n}$ is the normal vector on conductor surfaces; $\mu_{0}$ is the vacuum relative permeability at $4 \pi \times 10^{7} \mathrm{H} / \mathrm{m} ; \mu_{\mathrm{r}}$ is the relative permeability; $\gamma_{0}$ is the vacuum dielectric constant at $10^{-9} / 36 \pi \mathrm{F} / \mathrm{m} ; \gamma_{\mathrm{r}}$ is the relative dielectric constant.

For metal components and winding, the electromagnetic induction and heat conduction are coupled as follows:

$$
\left\{\begin{array}{l}
0=\nabla \cdot\left(\lambda_{\text {solid }}(T) \nabla T\right)+Q_{\mathrm{e}}, \\
Q_{\mathrm{e}}=Q_{\mathrm{rh}}+Q_{\mathrm{ml}}=\frac{1}{2} \operatorname{Re}\left(\vec{J} \cdot \vec{E}^{*}\right)+\frac{1}{2} \operatorname{Re}\left(j \omega \vec{B} \cdot \vec{H}^{*}\right),
\end{array}\right.
$$

where $T$ is the temperature, $\mathrm{K}$; $\mathrm{Re}$ is the real part of imaginary number; $Q_{e}$ is the total electromagnetic loss density of components in transformer, $\mathrm{W} / \mathrm{m}^{3} ; Q_{\mathrm{rh}}$ and $Q_{\mathrm{ml}}$ are the electrical loss density and magnetic loss density, W/ $\mathrm{m}^{3}$ for winding and $\mathrm{W} / \mathrm{m}^{2}$ for metal component and oil tank surfaces; $\vec{E}^{*}$ and $\vec{H}^{*}$ are the conjugate complex numbers of $\vec{E}$ and $\vec{H} ; \lambda_{\text {solid }}$ is the thermal conductivity of metal components and oil tank, $\mathrm{W} /(\mathrm{m} \cdot \mathrm{K})$.

For the oil flow and heat transfer in the transformer, the continuity, momentum, and energy equations are formulated as follows:

$$
\begin{aligned}
\nabla \vec{v} & =0, \\
\rho(T)(\vec{v} \cdot \nabla \vec{v}) & =-\nabla p+\nabla \cdot\left[\left(\mu(T)+\mu_{t}\right)\left(\nabla \vec{v}+(\nabla \vec{v})^{T}\right)\right], \\
\rho(T)(\vec{v} \cdot \nabla T) & =\nabla \cdot\left[\left(\frac{\lambda(T)}{c_{p}(T)}+\frac{\mu_{t}}{\sigma_{T}}\right) \cdot(\nabla T)\right] .
\end{aligned}
$$

As for oil turbulent flow, the RNG $k-\varepsilon$ turbulence model [23] is adopted for the simulations, which are formulated as follows:

$$
\left\{\begin{array}{l}
k: \rho(T)(\vec{v} \cdot \nabla k)=\nabla \cdot\left[\left(\mu(T)+\frac{\mu_{t}}{\sigma_{k}}\right) \cdot \nabla k\right]+P_{k}-\rho(T) \varepsilon, \\
\varepsilon: \rho(T)(\vec{v} \cdot \nabla \varepsilon)=\nabla \cdot\left[\left(\mu(T)+\frac{\mu_{t}}{\sigma_{\varepsilon}}\right) \cdot \nabla \varepsilon\right]+\frac{c_{\varepsilon} \varepsilon}{k} P_{k}-c_{\varepsilon 2} \rho(T) \frac{\varepsilon^{2}}{k},
\end{array}\right.
$$

where $\vec{v}$ is the velocity vector, $\mathrm{m} / \mathrm{s} ; c_{\mathrm{p}}$ is the oil heat capacity, $\mathrm{J} /(\mathrm{kg} \cdot \mathrm{K}) ; \rho$ is the oil density, $\mathrm{Kg} / \mathrm{m}^{3} ; \lambda$ is the oil thermal conductivity, $\mathrm{W} /(\mathrm{m} \cdot \mathrm{K}) ; \mu_{\mathrm{t}}$ is the oil turbulent viscosity, $\mathrm{kg} /$ $(\mathrm{m} \cdot \mathrm{s}) ; \sigma_{\mathrm{T}}$ is the Prandtl number; $p$ is the pressure, $\mathrm{Pa} ; \mu$ is the oil dynamic viscosity, $\mathrm{kg} /(\mathrm{m} \cdot \mathrm{s}) ; k$ is the turbulent kinetic energy, $\mathrm{m}^{2} / \mathrm{s}^{2} ; \varepsilon$ is the turbulent dissipation rate, $\mathrm{m}^{2} / \mathrm{s}^{3} ; P_{\mathrm{k}}$ is the turbulent shear generation term, $\mathrm{kg} /\left(\mathrm{m} \cdot \mathrm{s}^{3}\right) ; \sigma_{\mathrm{k}}$ and $\sigma_{\varepsilon}$ are 
the Prandtl numbers in $k$ and $\varepsilon$ equations; $c_{\varepsilon 1}$ and $c_{\varepsilon 2}$ are the model constants in $k$ and $\varepsilon$ equations.

In the present study, the oil thermal properties change with temperature, which are formulated as follows (COMSOL Multiphysics 5.2 [20]):

$$
\begin{aligned}
\lambda(T) & =0.134-\left(8.05 \times 10^{-5}\right) \times T, \\
\mu(T) & =91.45-1.33 \times T+0.0078 \times T^{2}-\left(2.27 \times 10^{-5}\right) \times T^{3}, \\
c_{p}(T) & =-13408.15+123.04 \times T-0.34 \times T^{2}+\left(3.13 \times 10^{-4}\right) \times T^{3}, \\
\rho(T) & =1055.05-0.58 \times T-\left(6.41 \times 10^{-5}\right) \times T^{2} .
\end{aligned}
$$

The fluid-solid coupling heat transfer boundary condition is adopted at interface between oil and solid domains. The heat transfer on the outside surface of oil tank is considered as natural convective heat transfer with air, which is formulated as follows:

$$
-q=h\left(T_{\mathrm{env}}-T\right)
$$

where $T_{\text {env }}$ is ambient temperature at $293.15 \mathrm{~K} ; h$ is convective heat transfer coefficient on the outside surface of oil tank, $\mathrm{W} /\left(\mathrm{m}^{2} \cdot \mathrm{K}\right) ; q$ is heat flux density, $\mathrm{W} / \mathrm{m}^{2}$.

In the present study, the leakage magnetic fields in the transformer with full load and electromagnetic loss for different components with different load rates are analyzed, and the electromagnetic field equations are solved using direct solver MUMPS embedded in COMSOL Multiphysics 5.2 [20]. The governing equations for oil coupled with electromagnetic loss of different components are solved with iterative solver GMRES embedded in COMSOL Multiphysics 5.2 [20]. When all residuals of the calculations are less than $10^{-3}$, the computational results are considered to be convergent.

2.3. Grid Independence Test and Model Validations. Firstly, the grid independence test is performed (Figure 2). For electromagnetic loss computations, tetrahedral meshes were used for oil and core domains, and triangular prism meshes were used for coil domain. Since surface impedance boundary condition was adopted on the metal component surfaces and tank surface, the internal regions for the metal component and tank wall were not meshed, and triangular meshes were adopted on metal component surfaces and tank surface.

For heat transfer computations, the thickness of oil tank wall was neglected and the internal region for tank wall was not meshed. The metal components are meshed with tetrahedral grids and the meshing methods for oil, core, and coil regions are similar to those used for electromagnetic loss computations, and the grid part of the sharp corner is intensified for heat transfer computations. The electromagnetic loss densities for different regions in the transformer under full load with different computational grids are listed in Table 2. It is found that when the total grid number is 395 891, the electromagnetic loss densities for different regions are almost unchanged. Therefore, grid settings similar to the grid with total grid number of 395891 were used for the subsequent electromagnetic loss simulations.
The hot spot temperatures for different regions in the transformer under full load with different computational grids are listed in Table 3, where the grid convergence index (GCI) based on Richardson extrapolation method [24] is used to verify the grid independence of heat transfer computations. It is found that when the total grid number is 3560 081, the hot spot temperatures for different regions are quite close to the extrapolated values obtained using Richardson extrapolation method. Therefore, grid settings similar to the grid with total grid number of 3560081 were used for the subsequent heat transfer simulations.

Subsequently, the computational model and methods for electromagnetic loss and heat transfer simulations in transformer were validated. Short-circuit test and opencircuit test are often used to test electromagnetic loss for transformer design and factory inspection. For short-circuit test, the low-voltage coil is shorted out and high voltage coil is supplied with a certain voltage, which is the product of rated voltage and impedance percentage $(2.57 \%)$. For this case, the coil is working at rated current and the electromagnetic loss is mainly the Joule loss of coil. For open-circuit test, the low-voltage coil is shut off and high voltage coil is supplied with rated voltage. For this case, magnetic flux in the core is saturated and the electromagnetic loss is mainly the eddy current loss of core. In the present study, for open-circuit test, the calculated core loss is $1589.97 \mathrm{~W}$, which is quite close to the values calculated using Steinmetz's formula [25] (the value is $1606.94 \mathrm{~W}$ ) and engineering empirical correlation [26] (the value is 1 $597.01 \mathrm{~W})$. For short-circuit test, the calculated coil loss is 2 $274.64 \mathrm{~W}$, which is quite close to that calculated with Joule's law (the value is $2278.9 \mathrm{~W}$ ). Therefore, the computational model and methods for electromagnetic loss simulations in the present study are reliable.

As for flow and heat transfer process in transformer, the turbulent heat transfer in a three-dimensional cubic cavity as reported by Wang and Chen [27] is restudied here. The physical model for the cubic cavity is presented in Figure 3(a). It shows that the side length of cubic cavity is $2.44 \mathrm{~m}$, and all the cavity walls are adiabatic. A small cubic heat source is arranged on the cavity bottom center, and the heat source temperature is fixed at $309.82 \mathrm{~K}$. The air inlet slot is located on the upper part of left vertical wall, where the airflow rate is $0.1 \mathrm{~m}^{3} / \mathrm{s}$ and the inlet temperature is $295.35 \mathrm{~K}$. The air outlet slot is located on the lower part of right vertical wall, where the outlet pressure is kept at $0 \mathrm{~Pa}$. The nondimensional temperature distributions on the line- $\mathrm{AB}$ are presented and compared in Figure 3(b), where the position of point $A$ is $0.228 \mathrm{~m}$ $(x), 1.219 \mathrm{~m}(y)$, and $2.44 \mathrm{~m}(z)$, and the position of point $\mathrm{B}$ is $0.228 \mathrm{~m}(x), 1.219 \mathrm{~m}(y)$, and $0 \mathrm{~m}(z)$. It is found that the averaged deviation between present simulation results and experimental results of Wang and Chen [27] is 7.6\% and the maximal deviation is $19.4 \%$. Meanwhile, the averaged deviation between present simulation results and simulation results of Wang and Chen [27] is 5.7\% and the maximal deviation is $16.2 \%$. Therefore, the computational model and methods for flow and heat transfer simulations in the present study are reliable. 


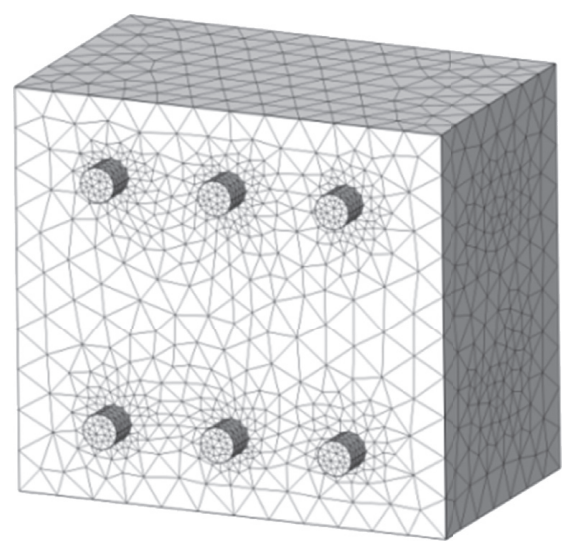

(a)

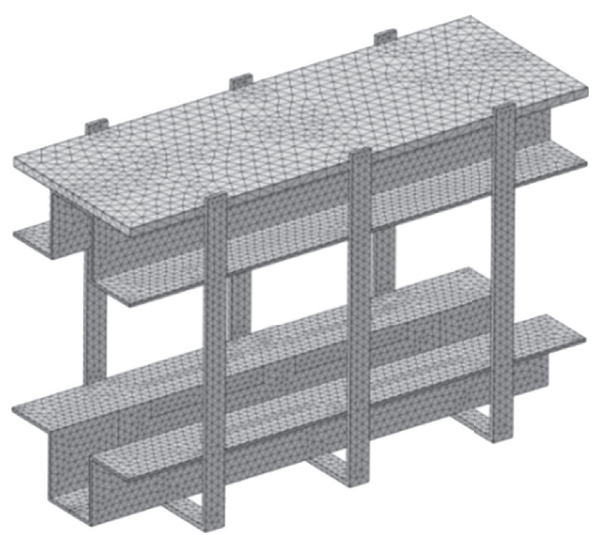

(b)

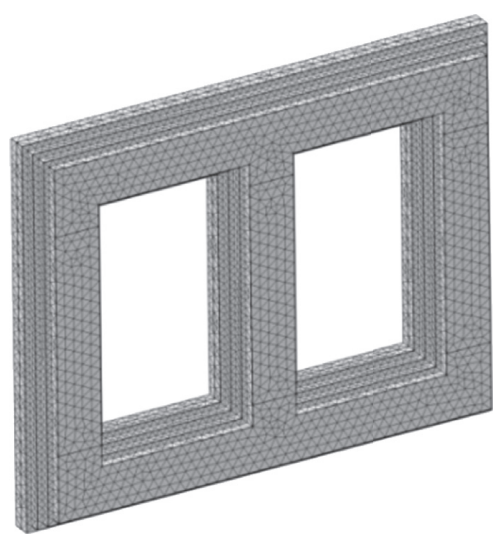

(c)

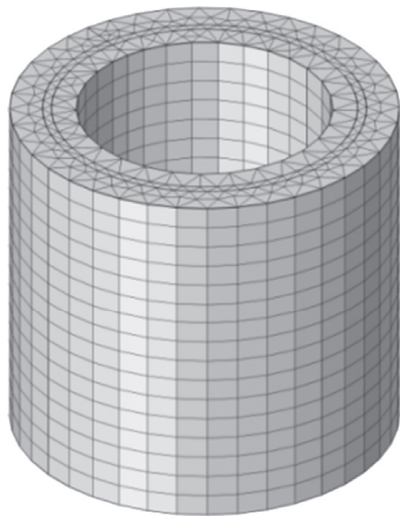

(d)

Figure 2: Computational mesh. (a) Oil tank. (b) Metal components. (c) Core. (d) Coil.

TABLE 2: Electromagnetic loss densities for different regions with different computational grids.

\begin{tabular}{|c|c|c|c|c|c|c|c|c|c|}
\hline $\begin{array}{l}\text { Total grid } \\
\text { numbers }\end{array}$ & Regions & $\begin{array}{l}\text { Maximal grid } \\
\text { size }(\mathrm{cm})\end{array}$ & $\begin{array}{l}\text { Minimal grid } \\
\text { size }(\mathrm{cm})\end{array}$ & $\begin{array}{c}\text { Grid } \\
\text { numbers }\end{array}$ & $\begin{array}{c}\text { Metal } \\
\text { components } \\
\left(\mathrm{W} / \mathrm{m}^{2}\right)\end{array}$ & $\begin{array}{l}\text { Oil tank } \\
\left(\mathrm{W} / \mathrm{m}^{2}\right)\end{array}$ & $\begin{array}{l}\text { HV coil } \\
\left(\mathrm{W} / \mathrm{m}^{3}\right)\end{array}$ & $\begin{array}{l}\mathrm{LV} \text { coil } \\
\left(\mathrm{W} / \mathrm{m}^{3}\right)\end{array}$ & $\begin{array}{c}\text { Core } \\
\left(\mathrm{W} / \mathrm{m}^{3}\right)\end{array}$ \\
\hline \multirow{5}{*}{218624} & Core & 4.96 & 1.90 & 57147 & \multirow{5}{*}{16.56} & \multirow{5}{*}{0.61} & \multirow{5}{*}{22137} & \multirow{5}{*}{30600} & \multirow{5}{*}{10809} \\
\hline & Coil & 5.42 & 4.04 & 3540 & & & & & \\
\hline & $\begin{array}{c}\text { Metal } \\
\text { component }\end{array}$ & 7.07 & 1.47 & 21008 & & & & & \\
\hline & Oil & 26.81 & 1.11 & 157937 & & & & & \\
\hline & Oil tank & 24.27 & 6.46 & 1278 & & & & & \\
\hline \multirow{5}{*}{395891} & Core & 4.51 & 1.61 & 100343 & \multirow{5}{*}{16.62} & \multirow{5}{*}{0.61} & \multirow{5}{*}{22072} & \multirow{5}{*}{30833} & \multirow{5}{*}{10831} \\
\hline & Coil & 3.60 & 2.52 & 13311 & & & & & \\
\hline & $\begin{array}{c}\text { Metal } \\
\text { component }\end{array}$ & 6.50 & 1.11 & 33630 & & & & & \\
\hline & Oil & 23.25 & 1.11 & 282237 & & & & & \\
\hline & Oil tank & 18.66 & 5.78 & 1970 & & & & & \\
\hline \multirow{5}{*}{713851} & Core & 2.93 & 1.23 & 237521 & \multirow{5}{*}{16.77} & \multirow{5}{*}{0.61} & \multirow{5}{*}{22064} & \multirow{5}{*}{30828} & \multirow{5}{*}{10815} \\
\hline & Coil & 3.61 & 2.02 & 24240 & & & & & \\
\hline & $\begin{array}{c}\text { Metal } \\
\text { component }\end{array}$ & 5.96 & 1.19 & 51438 & & & & & \\
\hline & Oil & 16.78 & 1.40 & 452090 & & & & & \\
\hline & Oil tank & 12.19 & 8.26 & 3968 & & & & & \\
\hline
\end{tabular}


TABLE 3: Hot spot temperatures for different regions with different computational grids.

\begin{tabular}{|c|c|c|c|c|c|c|c|}
\hline $\begin{array}{l}\text { Total grid } \\
\text { numbers }\end{array}$ & Regions & $\begin{array}{l}\text { Maximal grid size } \\
(\mathrm{cm})\end{array}$ & $\begin{array}{l}\text { Minimal grid size } \\
(\mathrm{cm})\end{array}$ & $\begin{array}{c}\text { Grid } \\
\text { numbers }\end{array}$ & $\begin{array}{l}\text { Hot spot } \\
(\mathrm{K})\end{array}$ & $\begin{array}{l}\text { Extrapolated value } \\
(\mathrm{K})\end{array}$ & $\begin{array}{c}\text { GCI number } \\
(\%)\end{array}$ \\
\hline \multirow{4}{*}{923456} & Core & 5.83 & 1.67 & 41736 & \multirow{4}{*}{383.38} & \multirow{12}{*}{366.79} & \multirow{12}{*}{0.9} \\
\hline & Coil & 3.14 & 1.14 & 44712 & & & \\
\hline & $\begin{array}{c}\text { Metal } \\
\text { component }\end{array}$ & 6.01 & 1.06 & 41746 & & & \\
\hline & Oil & 15.04 & 1.01 & 795262 & & & \\
\hline \multirow{4}{*}{1812723} & Core & 5.44 & 1.25 & 78400 & \multirow{4}{*}{373.45} & & \\
\hline & Coil & 2.11 & 1.01 & 83040 & & & \\
\hline & $\begin{array}{l}\text { Metal } \\
\text { component }\end{array}$ & 4.87 & 1.16 & 99138 & & & \\
\hline & Oil & 14.01 & 0.95 & 1552145 & & & \\
\hline \multirow{4}{*}{3560081} & Core & 5.24 & 1.00 & 195172 & \multirow{4}{*}{369.46} & & \\
\hline & Coil & 1.90 & 0.86 & 149100 & & & \\
\hline & $\begin{array}{c}\text { Metal } \\
\text { component }\end{array}$ & 4.87 & 0.78 & 195745 & & & \\
\hline & Oil & 11.11 & 0.72 & 3020064 & & & \\
\hline
\end{tabular}

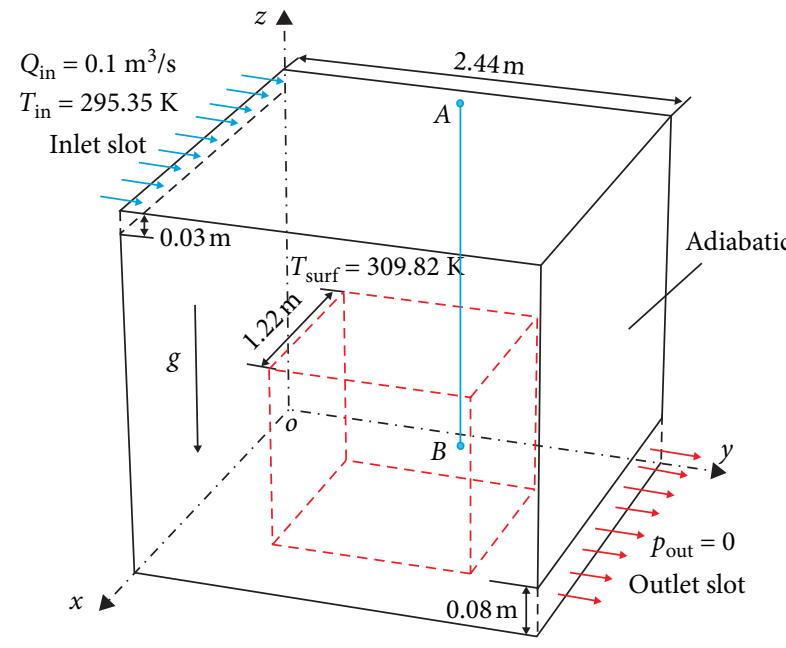

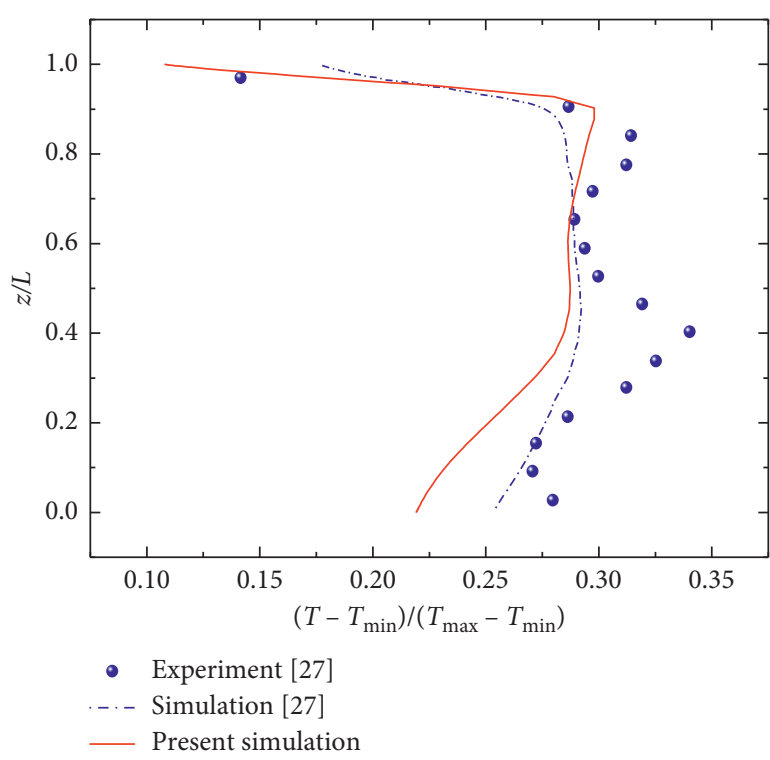

(b)

Figure 3: Physical model and nondimensional temperature distributions. (a) Physical model [27]. (b) Nondimensional temperature distributions on line-AB.

\section{Results and Discussion}

3.1. Leakage Magnetic Field and Electromagnetic Loss. When the transformer is fully loaded, both the high and lowvoltage coils are working under rated current and rated voltage. The magnetic excitation in the core generated by alternating electric field is main magnetic flux, which is saturated for fully loaded situation. Meanwhile, metal components and oil tank are intersected by leakage magnetic flux and a new circuit is formed on their surfaces, which will produce eddy current losses. For fully loaded situation, electromagnetic losses in transformer include copper loss of coil, iron loss of core, and eddy current loss on the surfaces of metal components and oil tank.
Logarithmic magnetic flux distributions of metal components and oil tank under fully loaded situation are presented in Figure 4. From Figure 4(a), it is shown that the leakage magnetic flux of metal components is mainly concentrated on component inner surfaces (facing the winding) and the maximal magnetic flux density is located at the contact part of core. Since leakage magnetic flux is mainly generated on the upper and lower end faces of coil, the leakage magnetic flux on yoke clamp facing upper and lower end faces of coil is obviously larger than the leakage magnetic flux on pulling plates facing side surfaces of coil. From Figure 4(b), it is shown that the leakage magnetic flux on vertical sidewalls of oil tank is obviously larger than that on horizontal walls. Due to magnetic shielding effect of 


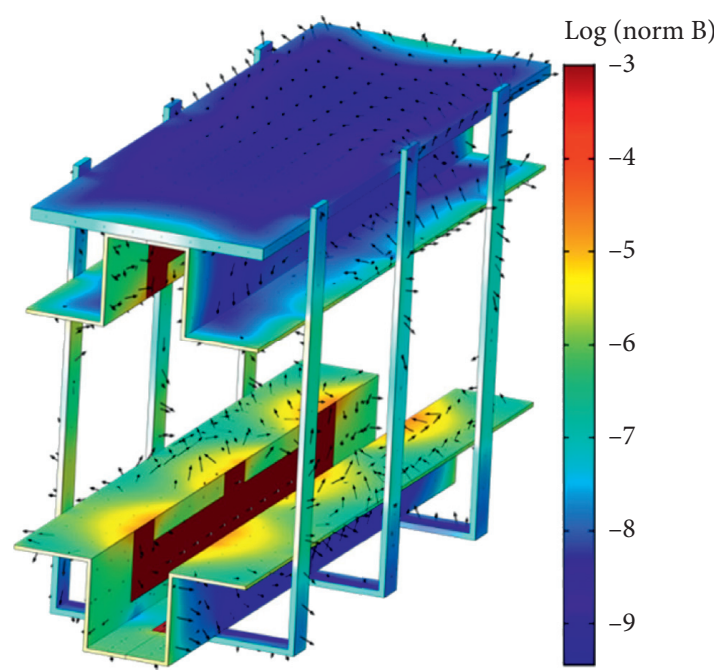

(a)

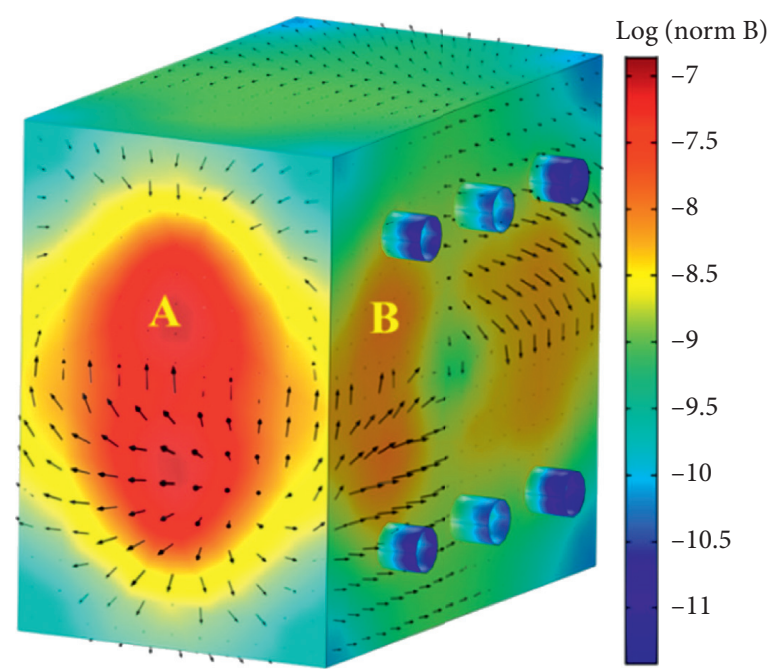

(b)

FIGURE 4: Logarithmic magnetic flux distributions of metal components and oil tank under fully loaded situation. (a) Metal components. (b) Oil tank.

metal components, the leakage magnetic flux cannot pass through yoke clamp and reach the top or bottom of oil tank. Therefore, the leakage magnetic flux on vertical sidewalls of oil tank is larger. Since the leakage magnetic fluxes between adjacent coils would be canceled out with each other, the leakage magnetic flux on sidewall A of oil tank is larger than that on sidewall $\mathrm{B}$.

Logarithmic surface current density and logarithmic eddy current loss density of metal components and oil tank under fully loaded situation are presented in Figure 5. From Figure 5(a), it is shown that surface current of metal components is generated by leakage magnetic flux, and surface current density is large when leakage magnetic flux concentrates. It is also shown that the induced current of contact part between yoke clamp and core is relatively small. Since the propagation direction of magnetic flux is not perpendicular to the surface of yoke clamp, a circuit loop will not be formed and the induced current is small. From Figure 5(b), it is shown that the induced currents generated by leakage magnetic flux superimpose at center of oil tank sidewall A as currents pass in and out of the wall. Therefore, the current density at center of oil tank sidewall $\mathrm{A}$ is the largest. It is also found that the induced currents generated by leakage magnetic flux are canceled out at center of oil tank sidewall $B$ as currents pass in and out of the wall. Therefore, the current density at center of oil tank sidewall $B$ is the smallest. In addition, from Figures 5(c) and 5(d), it is shown that the eddy current loss density distributions and current distributions on the surfaces of metal components and oil tank are similar, and the eddy current loss density on metal components' surfaces is obviously larger than that on oil tank surface.

Besides influence of leakage magnetic field, eddy current losses on the surfaces of metal components and oil tank are also affected by their own material properties. The variations of eddy current loss density on surfaces of metal components and oil tank with relative magnetic permeability are presented in Figure 6. It is shown that eddy current loss density on surfaces of metal components and oil tank obviously increases as relative magnetic permeability of metal components $\left(\mu_{1}\right)$ increases, while the effect caused by relative magnetic permeability of transformer tank $\left(\mu_{2}\right)$ is relatively small. Therefore, using metal components with small magnetic permeability would be beneficial to reduce electromagnetic loss in transformer.

For different load rates, the electromagnetic loss densities of different components in transformer are different, which would lead to different heat transfer performances in transformer. The electromagnetic loss densities of different components in transformer under different load rates are presented in Table 4. It is shown that as electromagnetic load rate increases, current densities of both high and low-voltage coils increase, and coil loss densities increase, while eddy current loss densities of core, metal components, and oil tank are almost unchanged. This is because eddy current loss is proportional to the square of induced voltage, which is correlated to magnetic flux density and frequency. The average magnetic flux densities in core and on surfaces of metal components and oil tank are almost unchanged with load rate (as shown in Table 5). Therefore, the eddy current loss densities of core, metal components, and oil tank are also almost unchanged.

3.2. Heat Transfer Performances in Transformer with Full Load. Temperature distributions for different components and oil velocity distributions in transformer under fully loaded situation are presented in Figure 7. It is shown that, for metal components, the hot spot temperature is $310.68 \mathrm{~K}$, which is located at contact place between core and inner surface of upper yoke clamp. The minimum temperature is $300.31 \mathrm{~K}$, which is located at the corner of pull plate (see Figure $7(\mathrm{a})$ ). For coil, the hot spot temperature is $369.46 \mathrm{~K}$, which is located at lower part of phase A low-voltage coil ( $30 \%$ height of coil). The minimum temperature is $342.67 \mathrm{~K}$, 


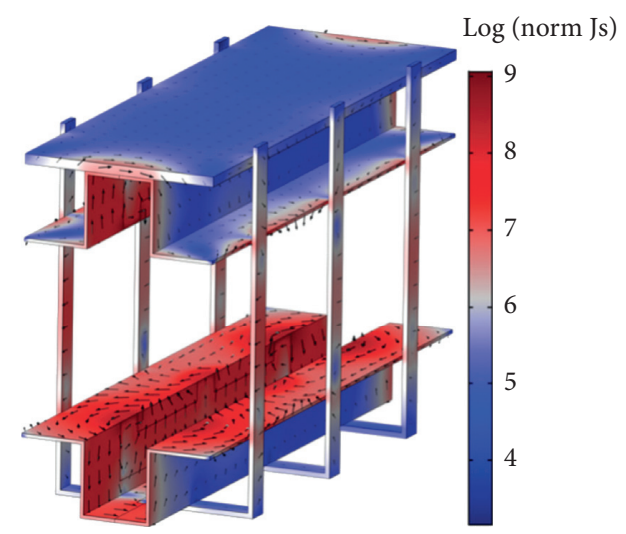

(a)

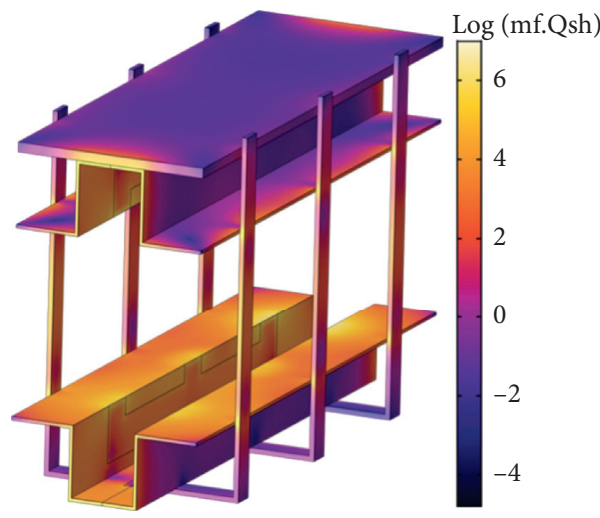

(c)

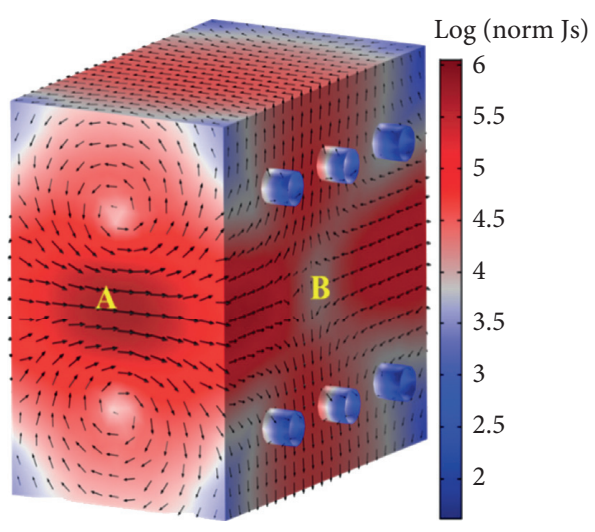

(b)

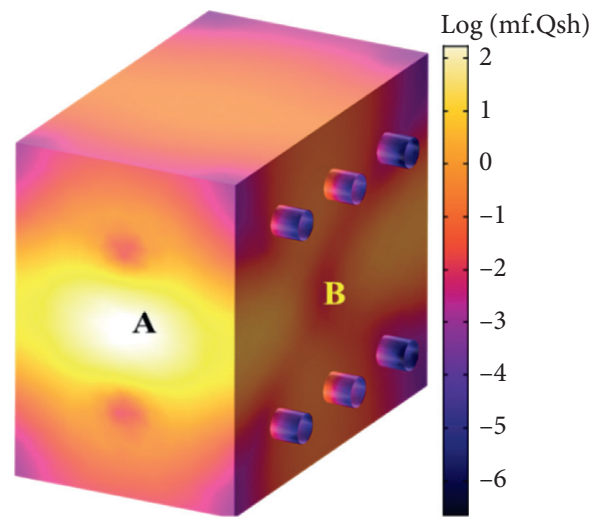

(d)

FIGURE 5: Logarithmic surface current density and logarithmic eddy current loss density of metal components and oil tank under fully loaded situation. (a) Surface current density of metal components. (b) Surface current density of oil tank. (c) Eddy current loss density of metal components. (d) Eddy current loss density of oil tank.

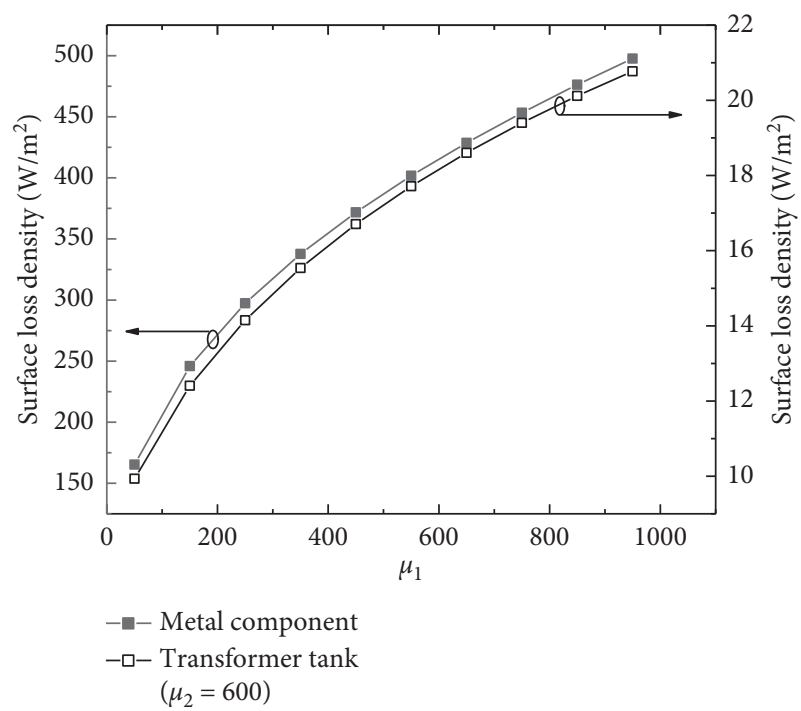

(a)

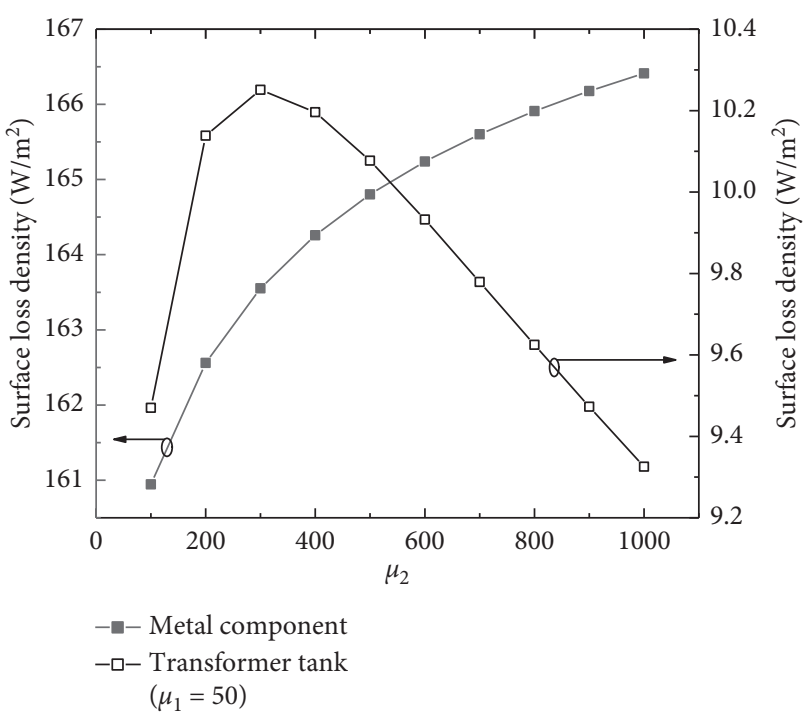

(b)

FiguRE 6: The variations of eddy current loss density on surfaces of metal components and oil tank with relative magnetic permeability. (a) Effect of relative magnetic permeability of metal components $\left(\mu_{1}\right)$. (b) Effect of relative magnetic permeability of oil tank $\left(\mu_{2}\right)$. 
TABle 4: Electromagnetic loss densities of different components in transformer under different load rates.

\begin{tabular}{lccccc}
\hline Load rate & Metal components $\left(\mathrm{W} / \mathrm{m}^{2}\right)$ & Tank wall $\left(\mathrm{W} / \mathrm{m}^{2}\right)$ & $\mathrm{HV}$ coil $\left(\mathrm{W} / \mathrm{m}^{3}\right)$ & $\mathrm{LV}$ coil $\left(\mathrm{W} / \mathrm{m}^{3}\right)$ & $\mathrm{Core}\left(\mathrm{W} / \mathrm{m}^{3}\right)$ \\
\hline 0.9 & 16.07 & 0.6 & 17966.04 & 24974.5 & 10836.92 \\
1.0 & 16.62 & 0.61 & 22071.73 & 30832.71 & 10831.05 \\
1.1 & 17.17 & 0.62 & 26607.55 & 37307.6 & 10824.88 \\
\hline
\end{tabular}

Table 5: Average magnetic flux densities of different components under different load rates.

\begin{tabular}{lccc}
\hline Load rate & Core $(\mathrm{T})$ & Metal components $(\mathrm{T})$ & Tank wall $(\mathrm{T})$ \\
\hline 0.9 & 1.57 & 0.11 & $1.81 \times 10^{-4}$ \\
1.0 & 1.57 & 0.11 & $1.83 \times 10^{-4}$ \\
1.1 & 1.57 & 0.11 & $1.85 \times 10^{-4}$ \\
\hline
\end{tabular}

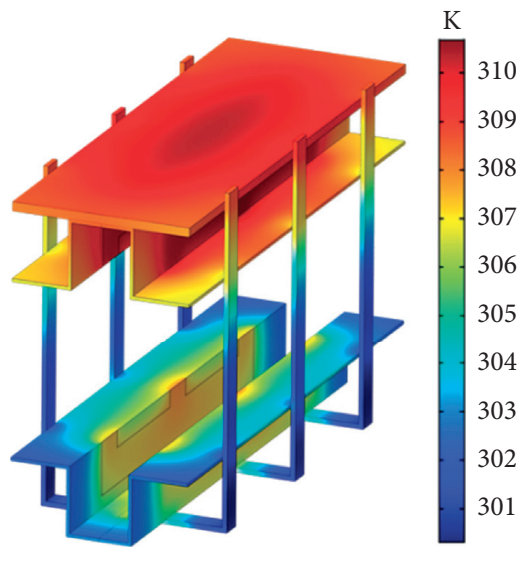

(a)

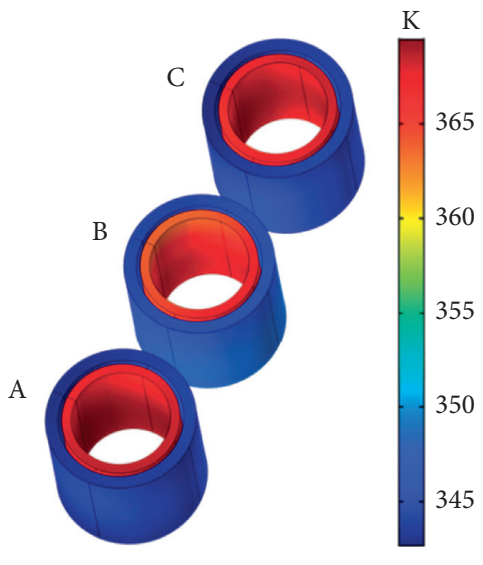

(b)

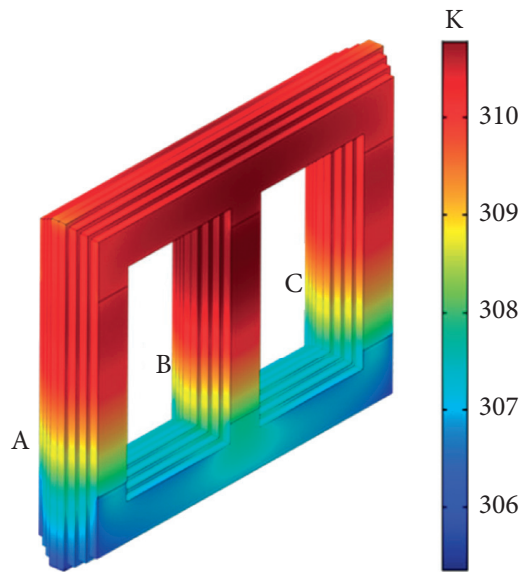

(c)

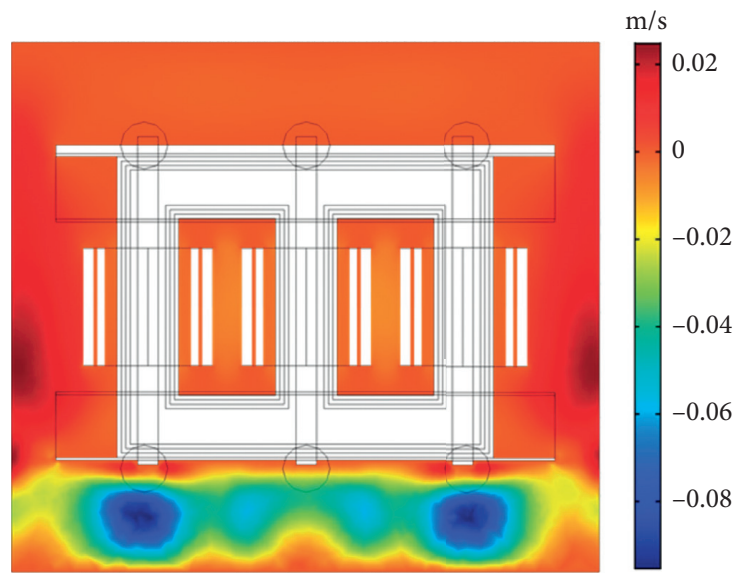

(d)

Figure 7: Temperature distributions for different components and oil velocity distributions in transformer under fully loaded situation. (a) Temperature distribution for metal components. (b) Temperature distribution for coil. (c) Temperature distribution for core. (d) Velocity distribution for oil ( $x-z$ section, $y=0$ ).

which is located on upper end face of phase A high voltage coil (see Figure 7(b)). For core, the hot spot temperature is $310.77 \mathrm{~K}$, which is located at upper part of phase B core column (73\% height of core). The minimum temperature is $305.36 \mathrm{~K}$, which is located at corner end of phase A core column (see Figure 7(c)). Moreover, from Figure 7(d), it is shown that oil flow vortices exist at bottom of oil tank and the heat transfer is better. Therefore, the temperatures at bottom of core and metal components are much lower.
Temperature distributions for winding and oil velocity distributions in transformer under fully loaded situation without consideration of eddy current losses on surfaces of metal components and oil tank are presented in Figure 8. It is shown that, for coil, the hot spot temperature is $332.61 \mathrm{~K}$, which is located at upper part of phase B low-voltage coil ( $85 \%$ height of coil). The minimum temperature is $322.23 \mathrm{~K}$, which is located on lower end face of phase B low-voltage coil (see Figure $8(\mathrm{a})$ ). For core, the hot spot temperature is 


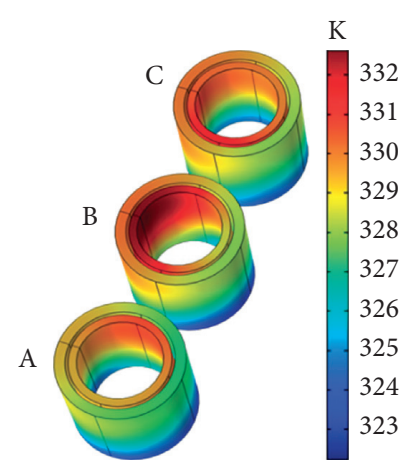

(a)

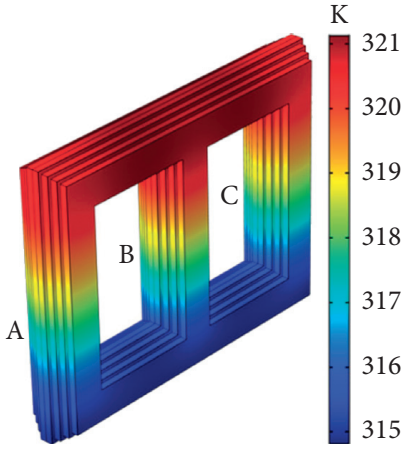

(b)

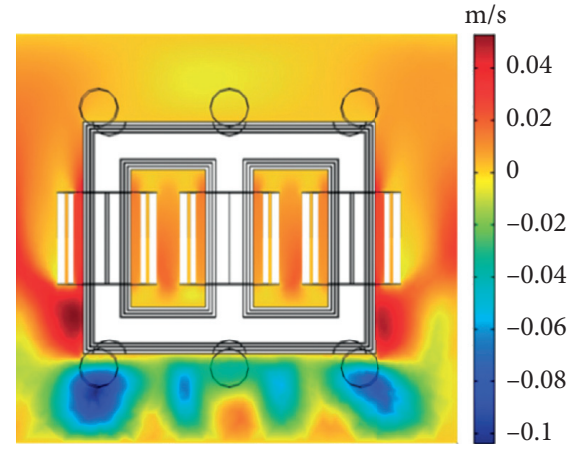

(c)

FIgURE 8: Temperature distributions for winding and oil velocity distributions in transformer under fully loaded situation (without eddy current losses on surfaces of metal components and oil tank). (a) Temperature distribution for coil. (b) Temperature distribution for core. (c) Velocity distribution for oil $(x-z$ section, $y=0)$.

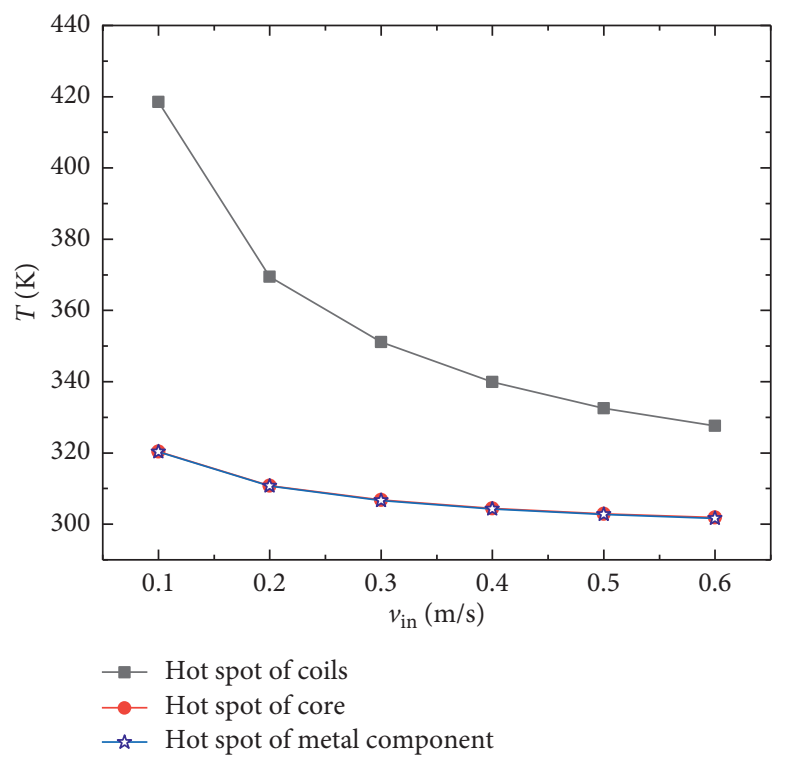

(a)

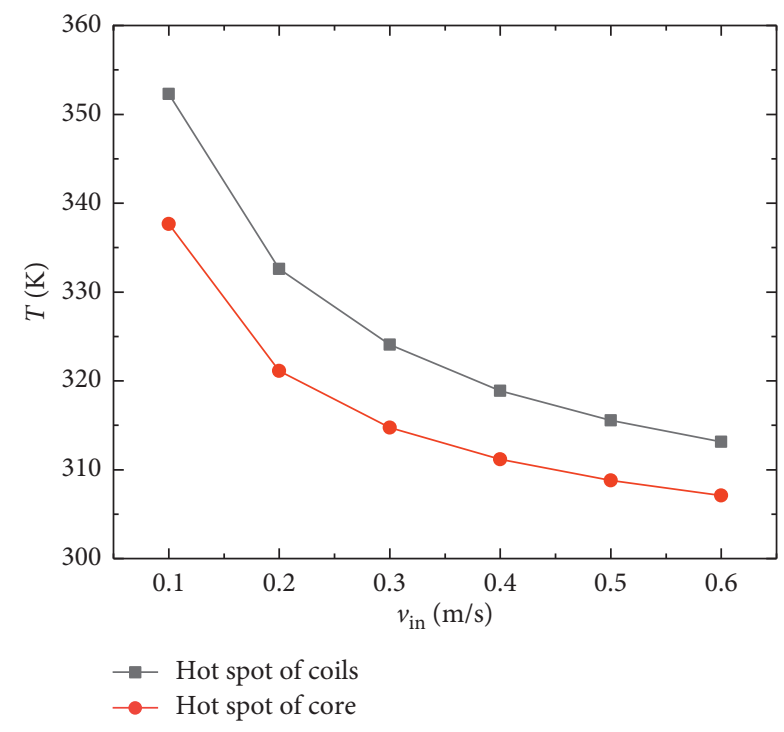

(b)

FIgURE 9: Variations of hot spot temperature for different components in transformer with oil inlet velocity under fully loaded situation. (a) With eddy current losses on surfaces of metal components and oil tank. (b) Without eddy current losses on surfaces of metal components and oil tank.

$321.13 \mathrm{~K}$, which is located at upper part of core (95\% height of core). The minimum temperature is $314.82 \mathrm{~K}$, which is located at corner end of phase C core column (see Figure 8(b)).

Comparing Figure 7 with Figure 8, it can be found that metal components would mix oil flow and change oil velocity distributions. Hot spot temperature of coil increases by $36.85 \mathrm{~K}$ due to extra eddy current losses on surfaces of metal components and oil tank, and temperature difference between the maximum coil temperature and minimum coil temperature also increases. Meanwhile, metal components would also promote oil flow disturbance near the core, which will enhance heat transfer between oil and core surface, and the hot spot temperature of core decreases by $10.36 \mathrm{~K}$. Furthermore, the hot spot locations of coil and core also change due to the changes of oil flow.
Variations of hot spot temperature for different components in transformer with oil inlet velocity under fully loaded situation are presented in Figure 9. It is shown that since core is fixed by yoke clamp, its hot spot position and temperature are almost the same. The hot spot temperatures of different components decrease as oil inlet velocity $\left(v_{\text {in }}\right)$ increases. When eddy current losses on surfaces of metal components and oil tank are considered, the coil's hot spot temperature decreases faster as $v_{\text {in }}$ increases, while the core's hot spot temperature decreases slowly. Meanwhile, as oil inlet velocity $\left(v_{\text {in }}\right)$ increases further, the decreasing tendency of hot spot temperatures for different components slows down. This may indicate that when inlet oil velocity $\left(v_{\text {in }}\right)$ is relatively high, the effect of inlet oil velocity $\left(v_{\text {in }}\right)$ on oil flow disturbance would be limited, and heat transfer enhancement for different components in transformer is not obvious. 


\section{Conclusions}

In the present paper, the electromagnetic losses of different components and heat transfer process in a three-phase forced oil circulation transformer $(400 \mathrm{kVA}-15 \mathrm{kV} / 400 \mathrm{~V})$ are numerically studied with finite element method. The leakage magnetic flux and eddy current loss density for metal components and oil tank are carefully analyzed, and the effect of metal components' electromagnetic loss on hot spot temperature of different components and oil flow in transformer is also studied. For present simulations, the variations of physical properties for different components and oil with temperature are fully considered. The major findings are as follows:

(1) The leakage magnetic flux of metal components is mainly concentrated on component inner surfaces and the maximal magnetic flux density is located at the contact part of core. The surface current of metal components is generated by leakage magnetic flux, and surface current density is large when leakage magnetic flux concentrates.

(2) The effect caused by relative magnetic permeability of metal components is remarkable on electromagnetic loss of metal components and oil tank, while the effect caused by relative magnetic permeability of transformer tank is relatively small. Using metal components with small magnetic permeability would be beneficial to reduce electromagnetic loss in transformer.

(3) Due to extra eddy current losses of metal components and oil tank, the hot spot temperature and inner temperature difference of coil increase. Meanwhile, due to the mixing of metal components on oil flow, the heat transfer of core is enhanced, its hot spot temperature is lowered, and the hot spot locations of coil and core also change.

\section{Nomenclature}

$\vec{A}$ : $\quad$ Magnetic vector potential $(\mathrm{Wb} / \mathrm{m})$

$\vec{B}: \quad$ Magnetic induction (T)

$c_{\mathrm{p}}: \quad$ Heat capacity of oil $(\mathrm{J} /(\mathrm{kg} \cdot \mathrm{K}))$

$c_{\mathrm{p}}, \quad$ Heat capacity of copper $(\mathrm{J} /(\mathrm{kg} \cdot \mathrm{K}))$

copper:

$c_{\mathrm{p}}$, iron: Heat capacity of iron $(\mathrm{J} /(\mathrm{kg} \cdot \mathrm{K}))$

$\underline{c_{\varepsilon 1}}, c_{\varepsilon 2}:$ Turbulence model parameters

$\vec{E}: \quad$ Electric field strength (N/C)

$\vec{E}_{s}$ : Tangential component of electric field strength $(\mathrm{N} / \mathrm{C})$

$\vec{E}^{*}$ : $\quad$ Conjugate complex number of electric field strength $\vec{E}$

$f: \quad$ Frequency, $50 \mathrm{~Hz}$

$\overrightarrow{H_{i}}: \quad$ Magnetic field strength $(\mathrm{A} / \mathrm{m})$

$\vec{H}^{*}$ : $\quad$ Conjugate complex number of magnetic field strength $\vec{H}$

$h$ : Convection heat transfer coefficient between tank

and air $\left(\mathrm{W} /\left(\mathrm{m}^{2} \cdot \mathrm{K}\right)\right)$

$\vec{J}: \quad$ Current density $\left(\mathrm{A} / \mathrm{m}^{2}\right)$

$j: \quad$ Imaginary unit

$k: \quad$ Turbulent kinetic energy $\left(\mathrm{m}^{2} / \mathrm{s}^{2}\right)$

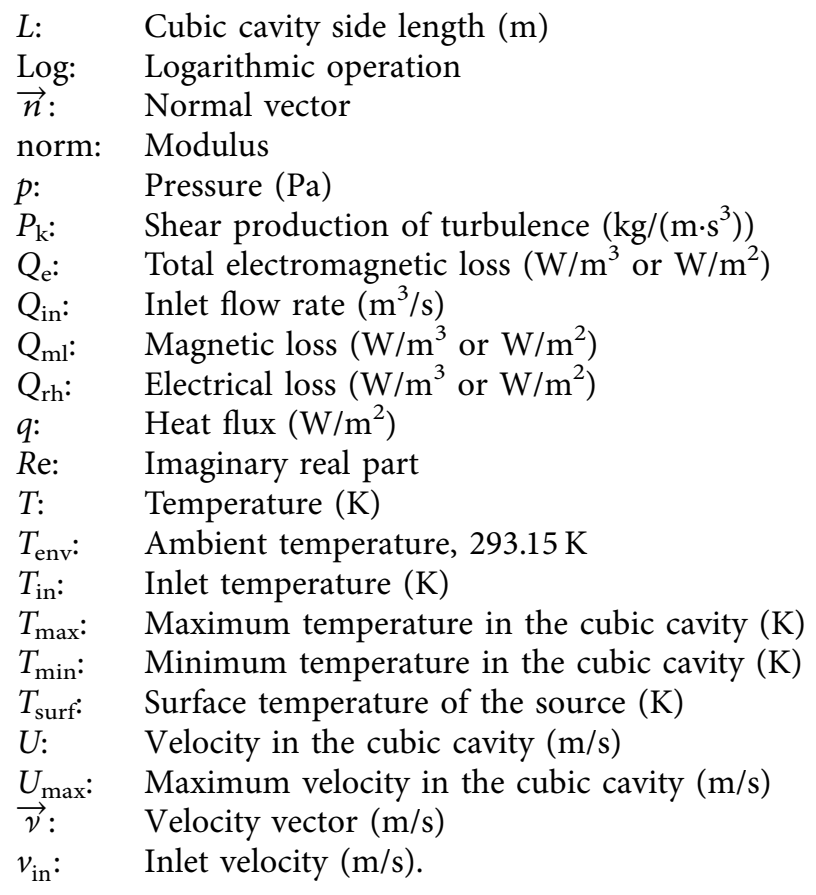

Greek letters

$\gamma: \quad$ Dielectric constant (F/M)

$\gamma_{\mathrm{r}}$ : Relative dielectric constant

$\gamma_{0}$ : Vacuum dielectric constant, $10^{-9} / 36 \pi \mathrm{F} / \mathrm{m}$

$\delta: \quad$ Skin depth $(\mathrm{m})$

$\varepsilon: \quad$ Turbulent dissipation rate $\left(\mathrm{m}^{2} / \mathrm{s}^{3}\right)$

$\lambda: \quad$ Thermal conductivity of oil $(\mathrm{W} /(\mathrm{m} \cdot \mathrm{K}))$

$\lambda_{\text {copper }}$ : Thermal conductivity of copper $(\mathrm{W} /(\mathrm{m} \cdot \mathrm{K}))$

$\lambda_{\text {iron: }}$ Thermal conductivity of iron $(\mathrm{W} /(\mathrm{m} \cdot \mathrm{K})$ )

$\lambda_{\text {solid }}$ : Thermal conductivity in equation $(5)(\mathrm{W} /(\mathrm{m} \cdot \mathrm{K}))$

$\mu$ : $\quad$ Magnetic permeability $(\mathrm{H} / \mathrm{m})$ or oil dynamic viscosity $(\mathrm{Pa} \cdot \mathrm{s})$

$\mu_{\mathrm{r}}: \quad$ Relative permeability of core

$\mu_{\mathrm{t}}: \quad$ Turbulent viscosity $(\mathrm{kg} /(\mathrm{m} \cdot \mathrm{s}))$

$\mu_{0}: \quad$ Vacuum permeability, $4 \pi \times 10^{7} \mathrm{H} / \mathrm{m}$

$\mu_{1}$ : $\quad$ Relative magnetic permeability of metal components

$\mu_{2}$ : $\quad$ Relative magnetic permeability of transformer tank

$\mu^{\prime}: \quad$ Real part of relative permeability

$\mu^{\prime \prime}$ : Imaginary part of relative permeability

$\rho: \quad$ Oil density $\left(\mathrm{kg} / \mathrm{m}^{3}\right)$

$\sigma: \quad$ Electrical conductivity $(\mathrm{S} / \mathrm{m})$ or Prandtl number

$\omega$ : $\quad$ Phase angle $\left({ }^{\circ}\right)$.

Subscripts

copper: Copper material

env: External environment

in: Inlet

iron: Iron material

max: Maximum

min: Minimum

solid: Solid domain

surf: Surface.

Abbreviations

$\mathrm{HV}$ : High voltage

GCI: Grid convergence index

LV: Low voltage. 


\section{Data Availability}

The data used to support the findings of this study are included within the article.

\section{Conflicts of Interest}

The authors declare that there are no conflicts of interest regarding the publication of this paper.

\section{Acknowledgments}

This work was supported by the S\&T project of State Grid Corporation of China "Research and application of key technologies of integrated ultrasonic and UHF PD coupling and sensing in transformer" under Grant no. 52094019000S.

\section{References}

[1] R. Jia, Y. T. Xie, H. Wu et al., "Power transformer partial discharge fault diagnosis based on multidimensional feature region," Mathematical Problems in Engineering, vol. 2016, Article ID 4835694, 11 pages, 2016.

[2] C. Yan, M. X. Liu, and W. Liu, "Transformer fault diagnosis based on BP-Adaboost and PNN series connection," Mathematical Problems in Engineering, vol. 2019, Article ID 1019845, 10 pages, 2019.

[3] S. Acharya and P. C. Tapre, "Life assessment of transformer using thermal models," in Proceedings of the 2017 International Conference on Energy, Communication, Data Analytics and Soft Computing (ICECDS), pp. 3515-3520, Chennai, India, August 2017.

[4] G. Swift, T. S. Molinski, and W. Lehn, "A fundamental approach to transformer thermal modeling. I. theory and equivalent circuit," IEEE Transactions on Power Delivery, vol. 16, no. 2, pp. 171-175, 2001.

[5] Z. R. Radakovic and M. S. Sorgic, "Basics of detailed thermalhydraulic model for thermal design of oil power transformers," IEEE Transactions on Power Delivery, vol. 25, no. 2, pp. 790-802, 2010.

[6] E. Hajidavalloo and M. Mohamadianfard, "Effect of sun radiation on the thermal behavior of distribution transformer," Applied Thermal Engineering, vol. 30, no. 10, pp. 1133-1139, 2010.

[7] B. R. Sathyanarayana, G. T. Heydt, and M. L. Dyer, "Distribution transformer life assessment with ambient temperature rise projections," Electric Power Components and Systems, vol. 37, no. 9, pp. 1005-1013, 2009.

[8] M. Ebenezer, R. M. Ramachandralal, and C. N. P. Pillai Sarasamma, "Study and analysis of the effect of harmonics on the hot spot temperature of a distribution transformer using finite-volume method," Electric Power Components and Systems, vol. 43, no. 20, pp. 2251-2261, 2015.

[9] F. Torriano, P. Picher, and M. Chaaban, "Numerical investigation of $3 \mathrm{D}$ flow and thermal effects in a disc-type transformer winding," Applied Thermal Engineering, vol. 40, pp. 121-131, 2012.

[10] M. A. Tsili, E. I. Amoiralis, A. G. Kladas, and A. T. Souflaris, "Power transformer thermal analysis by using an advanced coupled 3D heat transfer and fluid flow FEM model," International Journal of Thermal Sciences, vol. 53, pp. 188-201, 2012.
[11] C. B. Liao, J. J. Ruan, C. Liu et al., "Comprehensive analysis of 3-D electromagnetic-fluid-thermal fields of oil-immersed transformer," Electric Power Automation Equipment, vol. 35, no. 9, pp. 150-155, 2015.

[12] G. Liu, Y. J. Jing, Y. Q. Ma et al., "Numerical analysis of fluid field and temperature field of oil-immersed transformer," Transformer, vol. 54, no. 5, pp. 22-26, 2017.

[13] E. Agheb and H. K. Høidalen, "Modification of empirical core loss calculation methods including flux distribution," IET Electric Power Applications, vol. 7, no. 5, pp. 381-390, 2013.

[14] Z. B. Lan, W. Wen, J. J. Ruan et al., "Analysis of multi-physical field in ventilated dry-type transformer with FEM method," High Voltage Apparatus, vol. 51, no. 8, pp. 107-113, 2015.

[15] S. Magdaleno-Adame, J. C. Olivares-Galvan, P. PenabadDuran, R. Escarela-Perez, and I. Lopez-García, "Fast computation of hot spots temperature due to high current cable leads in power transformers tank walls," International Transactions on Electrical Energy Systems, vol. 25, no. 12, pp. 3374-3383, 2014.

[16] A. M. Milagre, M. V. Ferreira da Luz, G. M. Cangane et al., "3D calculation and modeling of eddy current losses in a large power transformer," in Proceedings of the 2012 XXth International Conference on Electrical Machines (ICEM), pp. 2282-2286, IEEE, Marseille, France, September 2012.

[17] M. Moghaddami, A. I. Sarwat, and F. De Leon, "Reduction of stray loss in power transformers using horizontal magnetic wall shunts," IEEE Transactions on Magnetics, vol. 53, no. 2, pp. 1-7, 2017.

[18] A. Njafi, I. Iskender, and B. Dokmetas, "Estimation of stray loss and leakage flux in the structural component of 3-phase distribution transformer under unbalanced voltage based on numerical analysis," in Proceedings of the IEEE Sixth International Conference on Modeling, Simulation and Applied Optimization, IEEE, Istanbul, Turkey, May 2015.

[19] L. C. Li, H. Rao, X. Z. Dong et al., "Prospect of computational high voltage engineering," High Voltage Engineering, vol. 44, no. 11, pp. 3441-3452, 2018.

[20] COMSOL, Multiphysics ${ }^{\circledR}$ v. 5.2. COMSOL AB, Stockholm, Sweden, 2016.

[21] COMSOL, Multiphysics, AC/DC Module User's Guide, COMSOL Multiphysics ${ }^{\circledR}$ v. 5.2, COMSOL AB, Stockholm, Sweden, 2016.

[22] L. Kralj and D. Miljavec, "Stray losses in power transformer tank walls and construction parts," in Proceedings of the 2010 XIX International Conference on Electrical Machines (ICEM), pp. 1-4, IEEE, Rome, Italy, September 2010.

[23] J. Gastelurrutia, J. C. Ramos, G. S. Larraona, A. Rivas, J. Izagirre, and L. del Río, "Numerical modelling of natural convection of oil inside distribution transformers," Applied Thermal Engineering, vol. 31, no. 4, pp. 493-505, 2011.

[24] P. J. Roache, "Perspective: a method for uniform reporting of grid refinement studies," Journal of Fluids Engineering, vol. 116, no. 3, pp. 405-413, 1994.

[25] S. V. Kulkarni and S. A. Khaparde, Transformer Engineering: Design, Technology, and Diagnostics, China Machine Press, Beijing, China, second edition, 2017.

[26] G. Bertotti, "General properties of power losses in soft ferromagnetic materials," IEEE Transactions on Magnetics, vol. 24, no. 4, pp. 621-630, 1988.

[27] M. Wang and Q. Chen, “Assessment of various turbulence models for transitional flows in an enclosed environment (RP1271)," HVACङR Research, vol. 15, no. 6, pp. 1099-1119, 2009. 